\title{
Neuroleptic malignant syndrome: clinical expression, complication, course, and atypical clinical picture
}

\author{
Bouchra Oneib ${ }^{*}$ and Ouafae Zaimi
}

\begin{abstract}
Background: Neuroleptic malignant syndrome (NMS) is an uncommon and lethal side effect of neuroleptics. The clinical expression of this syndrome is diverse. Even with criteria diagnosis, it is hard to recognize it easily.

We report a series of 25 cases of NMS among patients hospitalized in psychiatric service at Oujda for 5 years. We have described the clinical characteristics of NMS in these patients, the treatments received, the management, and the course of this syndrome.

Results: Most of the patients are hospitalized for psychotic or affective disorders according to the Diagnostic and Statistical Manual of Mental Disorders (DSM V) criteria. 92\% of patients received conventional neuroleptic, and half of them were under the injectable form. No patient took long-acting injectable antipsychotics. $36 \%$ of patients received neuroleptics for the first time. NMS appeared in the first week after the admission in psychiatric service among 24 patients. The most common clinical and biological signs were muscular rigidity, the elevation of creatine phosphokinase (CPK), and alteration of blood pressure. Other symptoms were found in proportion varied between $24 \%$ and $72 \%$. $32 \%$ of the patients did not develop complications. One patient developed renal failure. All patients recovered, and no deaths were recorded.
\end{abstract}

Conclusions: Early recognition of NMS help to rescue patient. It is necessary to detect this syndrome even in the absence of main signs such as fever.

Keywords: Neuroleptic malignant syndrome, Atypical clinical expression, Complication, Course

\section{Background}

NMS is a rare and potentially fatal side effect linked to the use of antipsychotics and medications altering dopaminergic neurotransmission [1]. It is a potential lifethreatening emergency. This syndrome could happen in a proportion going from 0.02 to $3 \%$ [2, 3]. The mortality rate is $5.6 \%[4]$. Pope et al. suggest that we sometimes underestimate NMS than overestimating [5].

First-generation antipsychotics are the head causes of NMS. Subjects receiving large doses of neuroleptics are more frequently affected by this adverse event [6].

\footnotetext{
*Correspondence: boucha82@hotmail.com

Department of Psychiatry, Maternal Child Health and Mental Health Research Laboratory, CHU Mohammed VI, Faculty of Medicine, University Mohammed I, Oujda, Morocco
}

\section{Springer Open}

(c) The Author(s). 2021 Open Access This article is licensed under a Creative Commons Attribution 4.0 International License, which permits use, sharing, adaptation, distribution and reproduction in any medium or format, as long as you give appropriate credit to the original author(s) and the source, provide a link to the Creative Commons licence, and indicate if changes were made. The images or other third party material in this article are included in the article's Creative Commons licence, unless indicated otherwise in a credit line to the material. If material is not included in the article's Creative Commons licence and your intended use is not permitted by statutory regulation or exceeds the permitted use, you will need to obtain permission directly from the copyright holder. To view a copy of this licence, visit http://creativecommons.org/licenses/by/4.0/. ity, tremor, fever, activation, and instability of the autonomic nervous system, altered consciousness, and CPK elevation [7]. Usually, the syndrome can last 7 to 10 days. Some serious complications may result from NMS as rhabdomyolysis, myoglobinuria but the most serious one is acute renal failure.

The clinical features and criteria for the diagnosis of NMS are wide and heterogeneous. The diagnosis of NMS presents a challenge. Indeed, we cannot easily differentiate it from several medication conditions like malignant catatonia [8] and severe parkinsonian syndromes.

In our study, we investigated a series of cases of NMS that occurred during 5 years among hospitalized patients in psychiatric service at Oujda. 


\section{Methods}

Our study was a cross-sectional with retrospective recruitment on 4039 medical files, covering a period of 5 years, from March 01, 2015, to March 2020, involving inpatients hospitalized in the various psychiatric departments of The University Hospital Center of Mohammed VI of Oujda.

In our department, we decide that in these cases:

The change of class of neuroleptics

The first administration of neuroleptics

Any patient tolerate well neuroleptics

The sudden appearance of at least one single sign such as fever, rigidity, blood pressure lability, alteration of consciousness, and asthenia requires the achievement of the rate of CPK urgently and monitoring the patient's condition.

The selection of files is done according to these criteria.

Inclusion criteria:

- Adult patients aged over 18 years, hospitalized in psychiatric service for different mental illnesses, diagnosed according to DSM V and with the use of Mini International Neuropsychiatric Interview, and they are treated with antipsychotics of different classes.

- Had a NMS during their hospitalizations according to the criteria of the DSM Fifth Edition. NMS is diagnosed upon the existence of the following findings: exposure to dopamine-antagonists, mental status changes (confusion, stupor, coma), muscle rigidity, hyperthermia $>38{ }^{\circ} \mathrm{C}$, autonomic dysfunction such as sweating, tachycardia, altered or generally elevated arterial tension, tachypnea, urinary incontinence, besides of an elevated white blood cell, and elevated CPK [9].

- NMS was considered atypical if the patient present three of the above four core criteria (hyperthermia, rigidity, mental status changes, autonomic dysfunction, and elevated CPK) [10].

- Diagnostic confirmed by the intensive care doctors.

\section{Exclusion criteria:}

- Incomplete medical records

- Psychiatric diagnosis not established

- A concomitant organic disease which can distort the diagnosis of NMS (infections, system disease, drug intoxication, etc.).
Exploitation sheet:

Including sociodemographic characteristics, in particular, age and gender. Also, we specified for each patient his diagnosis of the disease meeting the criteria of the DSM V classification, the duration of evolution, follow-up, and a somatic pathology if it is associated. We identified the antipsychotic responsible for NMS, and we described the current symptoms of this side effect.

We mentioned the care provided to these patients, the treatment, and the complication of NMS.

The collection of data carried by a psychiatrist resident using an exploitation sheet.

We respected the anonymity and confidentiality of the data.

Ethics approval and consent to participate: patients and their families accepted to use their data recruited during their hospitalization.

\section{Results}

\section{Sociodemographic characteristics}

We analyzed 29 files' patients who presented a NMS during their hospitalizations. Four files were excluded from the study because they were incomplete.

The patients were 16 males and 9 females with a mean age of $40.45 \pm 9.772$ years, ranging from 22 years to 57 years (Table 1$)$.

\section{Diagnosis}

The diagnoses of the various psychiatric pathologies of the hospitalized patients posed according to the criteria DSM V. 32\% of the patients admitted for a relapse of

Table 1 Sociodemographic characteristics

\begin{tabular}{ll}
\hline Variables & $\%(\boldsymbol{n})$ \\
\hline Age & $40.45 \pm 9.772$ ans \\
Gender & $64(16)$ \\
Man & $36(9)$ \\
Women & \\
Marital status & $44(11)$ \\
Single & $40(10)$ \\
Married & $12(3)$ \\
Divorced & $4(1)$ \\
Widowed & \\
Profession & $76(19)$ \\
Without & $24(6)$ \\
With & $28(7)$ \\
Socio-economic level & \\
Low & \\
Medium &
\end{tabular}

*Means \pm standard deviation 
schizophrenic psychosis. $12 \%$ had a diagnosis of a bipolar disorder type I. $16 \%$ of patients presented a schizoaffective disorder, and $36 \%$ had a schizophreniform disorder or acute psychotic attack. One patient had a diagnosis of depression with psychotic characteristics (Table 2).

\section{Medical history and addictive behaviors}

Regarding medical and surgical history, $72 \%(n=18)$ of patients had no antecedent, 2 patients had diabetes type II, and 2 patients had hypertension associated with diabetes type 2 . One patient had epilepsy, one patient had a history of uterine fibroid, and another one suffered in the past from breast cancer. 16 patients did not use an addictive substance, 5 patients smoke cigarettes, and 4 patients smoke both tobacco and cannabis. All patients are with no history of NMS in past. No family history of NMS among these cases. The course of the disease and length of taking antipsychotics varies between 1 month and 38 years (Table 3 ).

\section{Clinical and biological features on SMN}

The earliest sign of NMS was rigidity observed among 21 patients, and 16 patients had both fever and rigidity during the first $24 \mathrm{~h}$.

\section{Core symptoms}

18 patients $(72 \%)$ had a high fever. Muscle rigidity was observed among 21 patients (84\%). Altered consciousness was noticed in 6 patients (24\%). All patients had abnormal or unstable blood pressure. The pulse accelerated amongst 19 patients (76\%), and tachypnea was observed in 18 patients (72\%). Sweating was noticed in 19 patients (76\%).

The elevation of CPK is almost present in $92 \%$ of patients (23). CPK level was between $800 \mathrm{UI} / \mathrm{L}$ and 213 $530 \mathrm{UI} / \mathrm{L}$. Leukocytosis was present in 14 cases (56\%), in one case, it reached $141000 / \mathrm{mm}^{3}$ (Table 4). 28\% of patients presented atypical NMS. 22 patients (92\%) had previously received butyrophenone (haloperidol), phenothiazine (chlorpromazine or levomepromazine), and half of these patients $(52 \%)$ received these neuroleptic in injectable form for 1 to 3 days. The 15-mg dose of haloperidol was reached in $52 \%$ of patients. Two patients had received benzamide (amisulpride) with a dose of 400

Table 2 Patients diagnosis

\begin{tabular}{lc}
\hline Diagnostic & $\%(\boldsymbol{n})$ \\
\hline Schizophrenia & $32(8)$ \\
Schizoaffective disorder & $16(4)$ \\
Acute psychotic attack & $36(9)$ \\
Bipolar disorder I & $12(3)$ \\
Depression with psychotic characteristics & $4(1)$ \\
\hline
\end{tabular}

Table 3 Disease duration

\begin{tabular}{ll}
\hline Disease duration & $\%(\boldsymbol{n})$ \\
\hline$<1$ month & $28(7)$ \\
1 month-6 months & $12(3)$ \\
6 months-5 years & $16(4)$ \\
$5-10$ years & $16(4)$ \\
$>10$ years & $28(7)$ \\
\hline
\end{tabular}

$\mathrm{mg}$ per day. One patient was under risperidone $(6 \mathrm{mg})$. Two patients took an antidepressant, fluoxetine $20 \mathrm{mg}$. We found that NMS occurred after first administration in 8 patients, and in one case, NMS appeared following the neuroleptic change. Half of the patients were under two neuroleptics with chlorpromazine with a dose of 75 $\mathrm{mg}$. No patient was taking long-acting injectable antipsychotics. $36 \%$ of cases received neuroleptics for the first time. 100\% were under an incisive neuroleptic (Table 5).

Table 4 NMS symptoms

\begin{tabular}{|c|c|}
\hline Symptoms & $n(\%)$ \\
\hline \multicolumn{2}{|l|}{$\mathrm{T}>38^{\circ} \mathrm{C}$} \\
\hline Present & $72(18)$ \\
\hline Absent & $28(7)$ \\
\hline \multicolumn{2}{|l|}{ CPK } \\
\hline Eleveted & $92(23)$ \\
\hline Not eleveted & $8(3)$ \\
\hline \multicolumn{2}{|l|}{ Rigidity } \\
\hline Present & $84(21)$ \\
\hline Absent & $16(4)$ \\
\hline \multicolumn{2}{|l|}{ Mental status changes } \\
\hline Altered consciousness & $24(6)$ \\
\hline Not altered & $76(19)$ \\
\hline \multicolumn{2}{|l|}{ Unstable blood pressure } \\
\hline Yes & $25(100 \%)$ \\
\hline No & $0(0 \%)$ \\
\hline \multicolumn{2}{|l|}{ Tachycardia } \\
\hline Yes & $76(19)$ \\
\hline No & $24(6)$ \\
\hline \multicolumn{2}{|l|}{ Diaphoresis } \\
\hline Yes & $76(19)$ \\
\hline No & $24(6)$ \\
\hline \multicolumn{2}{|l|}{ Tachypnea } \\
\hline Yes & $72(18)$ \\
\hline No & $28(7)$ \\
\hline \multicolumn{2}{|l|}{ Leukocytosis } \\
\hline Yes & $56(14)$ \\
\hline No & $44(11)$ \\
\hline
\end{tabular}


Table 5 Antipsychotics causatives of NMS

\begin{tabular}{ll}
\hline Antipsychotics & \% ( $)$ \\
\hline First-generation antipsychotics & $88(22)$ \\
Haloperidol & $88(22)$ \\
Phenothiazine & $88(22)$ \\
Second-generation antipsychotics & $12(3)$ \\
Amisulpride & $8(2)$ \\
Risperidone & $4(1)$ \\
Injectable form & $52(13)$ \\
Oral administration & $48(12)$ \\
\hline
\end{tabular}

NMS appeared 3 days after admission in psychiatric service among 9 patients. 15 patients developed this syndrome 6 days after admission. One patient presented this side effect 10 days after. 19 patients (76\%) transferred to resuscitation. $32 \%$ of patients experienced a favorable course without complications. Rhabdomyolysis is the most common complication in patients with NMS (28\%), followed by renal failure or coma in $12 \%$ of cases. Two patients presented acute respiratory distress, and two other patients experienced paresis.

All patients were treated with supportive care, as well as the discontinuation of antipsychotics. They received vigorous hydration and treatment to lower fever and blood pressure. Also, to prevent venous thromboembolism, patients took heparin. In the case of agitation, we used benzodiazepines except for one patient who received hemodialysis, and two patients were on oxygen therapy.

All patients recovered, and no deaths were recorded. The patient who received treatment for acute renal failure recovered after some sessions of hemodialysis. No one was treated with dantrolene or bromocriptine.

\section{Discussion}

NMS is infrequent [1]. According to some studies, estimates of its frequency vary from 0.7 to $2.2 \%$ of people receiving neuroleptics [11]. In our case, we retained 25 complete files of patients who had an NMS among 4039 hospitalizations over 5 years, so the prevalence of NMS was $0.7 \%$. It can confirm objectively, the rarity, and the diagnostic difficulty of this syndrome.

The average age of our group was $40.45 \pm 9.772$ years (22 years-57 years). Result concordant with the foundation of some publications, where the mean age of patients with the NMS was 40 years. However, cases of NMS published showed that NMS was observed for all age groups [12].

The one patient with schizophrenia who presented with renal failure and need many sessions of hemodialysis was aged 57 years. Indeed, aged patient can present severe NMS [13].

In our sample, $64 \%$ of patients were male. Some publications [14] suggest that NMS is twice as common in men since antipsychotics are used more differently by gender. Men are more likely to receive high doses of neuroleptics, as they present more positive symptoms, such as agitation and hostility. Indeed, psychomotor agitation also seems to be linked to the occurrence of NMS [15].

The majority of patients had schizophrenia, acute psychotic access, or mood disorders. In a review article on 20 cases of NMS, it showed that this syndrome happened more among patients with schizophrenia and mood disorders. In another synthesis, 11 of the 12 cases of NMS occurred to schizophrenic patients [16].

No patients of our series did before NMS. In literature, patients with a history of NMS have an increased risk of having a second NMS [17].

Our patients had no family history of NMS, according to some research, there is a genetic risk factor. For this, antipsychotics should be used with caution in patients with a family history of NMS [8].

Half of the patients received neuroleptic in injectable form and $36 \%$ received it for the first time, and $28 \%$ had already a somatic disease. In the literature, the first administration and parenteral administration of neuroleptic as well as an associated with a somatic disease are the first suspected risk factors responsible for the occurrence of NMS [18].

$92 \%$ of cases received a conventional neuroleptic, $52 \%$ of patients received an injectable form of haloperidol, $100 \%$ took an incisive neuroleptic, and $36 \%$ got two neuroleptics.

There is an evidence suggesting that the risk of NMS is minimized if single-agent therapy strategies are used [19].

Rapid parenteral drug administration, according to some research [20], is a risk factor for NMS. The use of "incisive" neuroleptics seems to be associated with a higher risk of neuroleptic NMS [21].

According to the literature, 26 years are the longlasting latency between the starting of neuroleptic treatment and the occurrence of NMS. In our study, we have one case with 38 years under neuroleptic before the onset of NMS.

NMS appeared after 3 days of admission in $40.9 \%$ of our patients. $13.6 \%$ of patients had NMS after 6 days of admission. Clinically, the prodromal phase is rapidly progressive, marked by the appearance or accentuation of the extrapyramidal effects of neuroleptics. Some neuro-vegetative disorders should suggest the diagnosis. The state phase, reached on average in 2 days, combines general signs, neuromuscular signs, disturbances of consciousness, and evocative biological signs [22]. 
Hyperthermia $\left(\mathrm{T}>38{ }^{\circ} \mathrm{C}\right)$ observed in $72 \%$ of patients diagnosed with NMS. The fever noted in the NMS is usually higher than $38{ }^{\circ} \mathrm{C}$ sometimes exceeding $41{ }^{\circ} \mathrm{C}$ [1]. However, this hyperthermia would be absent in $9 \%$ of the cases [23]. In our study, it was absent in $28 \%$ of patients, which can make it difficult to diagnose NMS.

Rigidity was observed in $84 \%$ of our patients. According to the authors, rigidity was found in 91 to $96 \%$ of cases [24], but there were cases for which no rigidity is reported [25].

CPK elevation is almost present in $92 \%$ of our patients. For the majority of authors, the CPK level is one of the most reliable elements for assessing the occurrence of NMS, which is present in the majority of NMS cases, but not all [26].

Leukocytosis is always almost present in half of the cases (56\%). Leukocytosis, with or without inversion of the blood formula, is also frequent according to the literature [27].

Consciousness or cognitive disorders during NMS mentioned in $24 \%$ of the patients in our sample. Stupor, coma, and catatonia are the cognitive disorders associated with NMS, according to the authors [24].

All patients had abnormal or labile blood pressure. The pulse accelerated by $76 \%$ of the patients and the tachypnea in $72 \%$. Sweating was noticed in $76 \%$ of people with NMS.

All these neurovegetative symptoms can lead to vasoconstriction, respiratory distress, and dehydration, hence the interest to monitor these symptoms [24].

The atypical features of NMS can group the cases where the patients do not present the major criteria of this syndrome. In our study, we found some patients who did not have a fever, muscle rigidity, or increased CPK. Should be reviewed the diagnostic criteria for this syndrome.

$32 \%$ of patients experienced a favorable course without complications or death. Resuscitation was required in $76 \%$ of cases.

Many complications appear in cases of an untreated or unrecognized malignant syndrome of neuroleptics: renal failure, coma, or rhabdomyolysis with repercussions that can be pejorative (4 times out of 120 cases) [15]. This shows that our patients were taken care of early and quickly, hence the importance of early diagnosis with good monitoring of the condition of any patient on neuroleptics.

Discontinuation of neuroleptic, supportive care was the principal treatment of NMS in our sample; effectively this is the first-line treatment. No deaths were recorded in our study. Indeed, NMS mortality rates have decreased due to early recognition of the syndrome with early and appropriate intervention. This awareness ensures fast and complete recovery.
That is true that NMS is less common, but some atypical forms can be hard to detect. So recognition of suspect cases and efficient management can save these patients.

\section{Conclusion}

The clinical picture of NMS is heterogeneous. Some patients did not fulfill all NMS criteria. It could be the result of the vigilance of clinicians who manage to screen for NMS before the onset of all symptoms. Or atypical antipsychotics are responsible for atypical clinical expression of NMS. Even in the absence of major criteria (like fever or rigidity), diagnosis of NMS should be considered, specially that we can use CPK which is an important distinguishing criterion of NMS. The early intervention can save the life of patients, and it is necessary to continue research in this area, as well as the continuous awareness of caregivers, to standardize convenient medical practices.

\section{Abbreviations}

NMS: Neuroleptic malignant syndrome; DSM: Diagnostic and Statistical Manual of Mental Disorders; CPK: Creatine phosphokinase

\section{Acknowledgements}

None

\section{Authors' contributions}

Both authors, $\mathrm{BO}$ and $\mathrm{OZ}$, contributed to the conception and design of the work, the acquisition, analysis, and interpretation of the data, and they have drafted the work and approved the submitted version. Both authors (BO and OZ) have read and approved the manuscript.

Funding

None

Availability of data and materials

The authors confirm that the data supporting the findings of this study are available within the article.

Ethics approval and consent to participate

Patients and their families accepted to use their data recruited during their hospitalization by signing a form.

Consent for publication

The both authors (BO and $\mathrm{OZ}$ ) have read and approved the manuscript.

Competing interests

None

Received: 3 November 2020 Accepted: 7 December 2020

Published online: 04 January 2021

\section{References}

1. Umbricht D (1996) Medical complication of new antipsychotic drugs. Schizophr Bull 22(3):475-483

2. Levenson JL (1985) Neuroleptic malignant syndrome. Am J Psychiatry 142: 1137

3. Velamoor VR (1998) Neuroleptic malignant syndrome. Recognition, prevention and management. Drug Saf 19:73

4. Pope HG, Keck PE Jr, McElroy SLB (1986) Frequency and presentation of neuroleptic malignant syndrome in a large psychiatric hospital. Am J Psychiatry 143:1227-1233

5. Modi S, Dharaiya D, Schultz L, Varelas P (2016) Neuroleptic malignant syndrome: complications, outcomes, and mortality. Neurocrit Care. 24(1):97103 
6. Ged E (1986) Traitement du delirium tremens par le tiapride et syndrome malin des neuroleptiques. Presse Mes 15(22):1047-1048

7. Caroff SN (1980) The neuroleptic malignant syndrome. J Clin Psychiatry 41 79-83

8. De Rohan-Chabot P (1990) Reconnaitre et traiter une hyperthermie maligne. In: Goulon M ( $2^{\text {nd }}$ ed) Les urgences: Reconnaitre, comprendre, traiter les urgences. Paris; Edisem, pp 642-646

9. American Psychiatric Association (1994) Neuroleptic Malignant Syndrome Diagnostic and Statistical Manual of Mental Disorders. Fourth Ed., Washington DC. pp. 739-742.

10. Picard LS, Lindsay S, Strawn J et al (2008) Atypical neuroleptic malignant syndrome: diagnostic controversies and considerations. Pharmacotherapy 28(4):530-535

11. Montgomery JN (1990) Neuroleptic malignant syndrome in the intensive therapy unit. Anaesthesia 45(4):311-313

12. Sc D (1993) Antipsychotic agents: a review. Am Pharm Physician 47(1):199204

13. George S, Streim J, Carpenter D, John P (2004) Docherty, expert consensus panel for using antipsychotic drugs in older patients. Using Antipsychotic Agents in Older Patients. J Clin Psychiatry 65(2):5-99 discussion 100-102: 103-4

14. Schibuk M (1986) A role for catecholamines in the pathogens of neuroleptic malignant syndrome. Can J Psychiatry 31:66-69

15. Jahan MS (1992) Neuroleptic malignant syndrome. J Natl Med Assoc 84: 966-970

16. Duarte J (1996) Neuroleptic malignant while on tiapride treatment. Clin Neuropharmacol 19(6):539-540

17. Guttrnacher LB (1994) Médicaments antipsychotiques (Neuroleptiques). In: Manuel Merck de. Diagnostic et Thérapeutique; 2 1552. Édition française, vol $147, \mathrm{p} 1543$

18. Delay J (1965) Sur quelques erreurs de prescription des médicaments psychiatriques. Bull Mem Soc Hop 116(5):487-493

19. Delerue $O$ (1990) Syndrome malin des neuroleptiques prolongés et à rechutes. Rev Neurol 146(8-9):515-517

20. De Reuck J (1991) Positron emission tomographie studies of changes in cerebral blood flow and oxygen metabolism in neuroleptic malignant syndrome. Eur Neurol 31(1):1-6

21. Figa-Talamanga L (1985) Hyperthermia after discontinuance of levodopa and bromocriptine therapy: impaired dopamine receptors a possible cause. Neurology 35:258-261

22. Guitera RJ (1996) Diaphoresis and dehydration during neuroleptic malignant syndrome: preliminary findings. Psychiatryes 64(2):137-145

23. Delay J (1968) Drug inducted extrapyramidal syndromes. Hand book of clinical neurology Vol 6. Vinken PJ, Bruyen GW; eds; Amsterdam; north holland; pp 248-266

24. Guitera RJ (1992) Sympatho-adrenomedullary activity in the neuroleptic malignant syndrome. Biol Psychiatry 32(4):334-343

25. Faigt R (1989) Syndrome malin des neuroleptiques et tiapride. J Toxicol Clin Exp 9(5):33-335

26. Rainer C (1991) Neuroleptic malignant syndrome. When levodopa withdrawal is the cause. Postgrad Med 89(5):175-180

27. Guze BH (1985) Current concepts: neuroleptic malignant syndrome. NEJM 313(3):163-166

\section{Publisher's Note}

Springer Nature remains neutral with regard to jurisdictional claims in published maps and institutional affiliations.

\section{Submit your manuscript to a SpringerOpen ${ }^{\circ}$ journal and benefit from:}

- Convenient online submission

- Rigorous peer review

- Open access: articles freely available online

- High visibility within the field

- Retaining the copyright to your article

Submit your next manuscript at $\boldsymbol{\nabla}$ springeropen.com 